Results: TOC therapy showed high efficacy in children with RF-negative polyarticular JIA: 81.8/67.3/47.3/23.6\% of patients reached the ACR30/50/70/90 criteria for the end of follow-up, respectively. The median time of achieving at least $30 \%$ improvement from baseline (ACR30) was 1 months (IQR 1:3).

Univariate analysis showed that earlier age at initiation of Tocilizumab therapy, higher physician's global assessment score using the 100-point Visual Analogue Scale, and longer morning stiffness were the factors associated with reaching ACR90. Younger age at therapy initiation, greater number of swollen joints and joints with limited range of motion, and history of using fewer biologicals are the factors associated with reaching inactive disease and remission. However, multifactorial analysis showed that only earlier age at initiation of TOC therapy was a statistically significant factor associated with reaching the best response to therapy in all the models.

Conclusions: Earlier initiation of TOC therapy is associated with higher chances for reaching ACR90 and pharmacological remission in patients with RF-negative polyarticular JIA. Further studies in larger cohorts are needed to identify the optimal age at therapy initiation.

Disclosure of Interest: E. Alexeeva: None declared, T. Dvoryakovskaya Grant/ research support from: Roche, Pfizer, M. Soloshenko: None declared, R. Denisova: None declared, K. Isaeva: None declared, A. Mamutova: None declared, V. Gladkikh: None declared, A. Moskalev: None declared DOI: 10.1136/annrheumdis-2018-eular.6487

\section{AB0432 BIOLOGIC DMARDS TREATMENT RETENTION IN PATIENTS WITH RHEUMATOID ARTHRITIS ACCORDING TO THE MOSCOW ARTHRITIS REGISTRY (MERA)}

E. Koltsova ${ }^{1}$, E. Zhilyaev ${ }^{2}$, G. Lukina ${ }^{3}$, E. Shmidt ${ }^{4} .{ }^{1}$ Research Institute of the Organization of health and healthcare management, ${ }^{2} \mathrm{CJSC}$ «European Medical Center »; ${ }^{3}$ Moscow Clinical Scientific Center, ${ }^{4}$ City Clinical Hospital 1 named after N.I. Pirogov, Moscow, Russian Federation

Background: Retention on treatment is a good index of efficacy and safety of treatment used in the real clinical practice. These data may be useful to planning the treatment among some years. ${ }^{12}$

Objectives: To compare the drug survival of biological therapies.

Methods: We followed rheumatoid arthritis patients treated with biologics DMARD and registered in MERA 2012-January 2018. All patients had more than one visit in the registry.

Results: We analysed 799 patients (mean age $57,3 \pm 13$, mean diseases duration $15,6 \pm 10,3$ years). The average time until a change of treatment for infliximab was 399 days - the shortest treatment duration. Abatacept (median survival - 2922 days) demonstrated significant superiority over adalimumab (1339 days) $(p<0.001)$, infliximab (399 days) $(p<0.001)$, rituximab (2557 days) $(p=0.004)$ and etanercept ( 1492 days) $(p=0.035)$ when they was used as the first biologic drug. Among second-line therapy, the longest treatment survival has etanercept (3435 days), the shortest - infliximab (212 days).

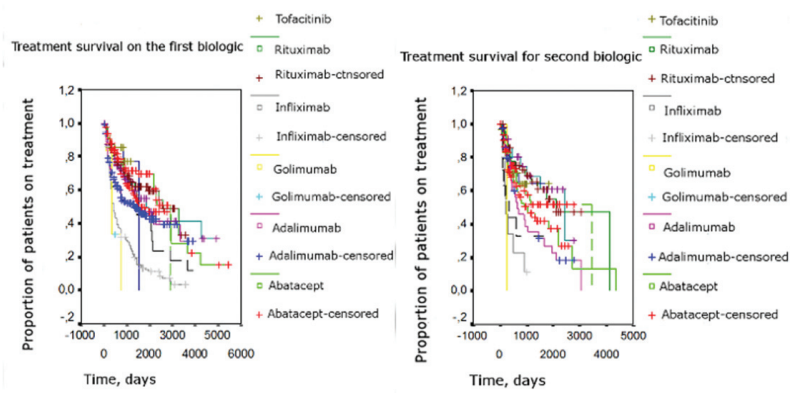

Abstract AB0432 - Figure 1

Conclusions: The results of the trial show the differences in treatment survival of some biologics. It can be reasonable to take these significant differences into consideration by the long-term planning of the biologic treatment of rheumatoid arthritis patients.

\section{REFERENCES:}

[1] Virginia Martinez-Santana, et al. Comparison of drug survival rates for tumor necrosis factor antagonists in rheumatoid arthritis. Patient Prefer Adherence 2013;7:719-727.

[2] Du Pan SM. Arthritis Rheum. Comparison of drug retention rates and causes of drug discontinuation between anti-tumor necrosis factor agents in rheumatoid arthritis 2009
Disclosure of Interest: None declared

DOI: 10.1136/annrheumdis-2018-eular.7173

\section{AB0433 PATIENTS WITH RHEUMATOID ARTHRITIS. REAL- WORLD DATA FROM THE RUSSIAN NORTH-WESTERN BIOLOGICAL TREATMENT COHORT}

E. Vasilenko, R.R. Samigullina, V.I. Mazurov, E.A. Trofimov, I.Z. Gaydukova. North-Western State Medical University named after I.I. Mechnikov, SanktPeterburg, Russian Federation

Background: Biologics are drugs that improved the status of rheumatoid arthritis (RA). At the same time real-world data (RWD) from large cohorts can give some additional information about efficacy and safety of the biological agents.

Objectives: The aim of the study was to analyse the efficacy and safety of biological treatment in large prospective cohort during 102 weeks of treatment.

Methods: The data from 1400 patients on biological treatment from North-Western State Medical University Biological Treatment Cohort Study (St. Petersburg, Russia) were analysed. In final analysis data from 758 patients with RA/EULAR 2010 criteria), were included. Following drugs were used: adalimumab $(n=22)$, certolizumab pegol $(n=62)$, etanercept $(n=64)$, golimumab $(n=21)$ and infliximab $(n=69)$, rituximab $(n=520)$ ). The disease activity index (DAS28) and high-sensitive C-reactive protein (C-RP) were evaluated as markers of RA activity. Side effects were registered during the study.

Results: RA activity, demographic characteristics, and concomitant treatmen (including methotrexate, glucocorticoids, NSAIDs, analgesics) at baseline were similar in all the treatment groups ( $p \geq 0.05$ for all the parameters). The faster response was found in golimumab and certolizumab pegol patients ( $p$ and It; 0.01 for difference of DAS28 in golimumab, certolizumab pegol treatment and other treatment groups at week 6), figure 1. After week 12 the similar efficacy of all the TNFa-blockers (figure 1).

RA activity, demographic characteristics, and concomitant treatment (including methotrexate, glucocorticoids, NSAIDs, analgesics) at baseline were similar in all the treatment groups ( $p \geq 0.05$ for all the parameters). The faster response was found in golimumab and certolizumab pegol patients $(p<0.01$ for difference of DAS28 in golimumab, certolizumab pegol treatment and other treatment groups at week 6), figure 1. After week 12 the similar efficacy of all the TNFa-blockers (fig ure 1).C-RP levels were similar in all the treatment groups in all time-points $(p \geq 0.05)$. DAS28 (mean $\pm S D$ ) in RA patients, treated with rituximab, at baseline and at weeks 24,54 , and 102 was $6.6 \pm 2.4,3.7 \pm 1.7,3.62 \pm 2.1$ and $3.2 \pm 2.05$, respectively; $p \geq 0.05$ for the differences with all another treatment groups at the same time-points.

The most frequent side-effects were opportunistic infections, OR=1.8 $[95 \% \mathrm{Cl}$ 1.4-2.1]. Risk of infections was higher in patients, receiving monoclonal antibodies to TNF $\alpha$, as compared to other TNF $\alpha$ inhibitors $(p<0.01$ for differences between infliximab/adalimumab/golimumab and etanercept, and $p<0.05$ for differences between infliximab/adalimumab/golimumab and certolizumab pegol).

The risk of cancer in RA patients on biological treatment and in total Russian population (including lymphomas and skin cancer) was comparable: for all the tumours $\mathrm{OR}=0.98[95 \% \mathrm{Cl} 0.76-1.26]$, for lymphomas $\mathrm{OR}=1.23[95 \% \mathrm{Cl} 0.92$ 1.41], for skin cancer $\mathrm{OR}=1.11[0.88-0.36]$.

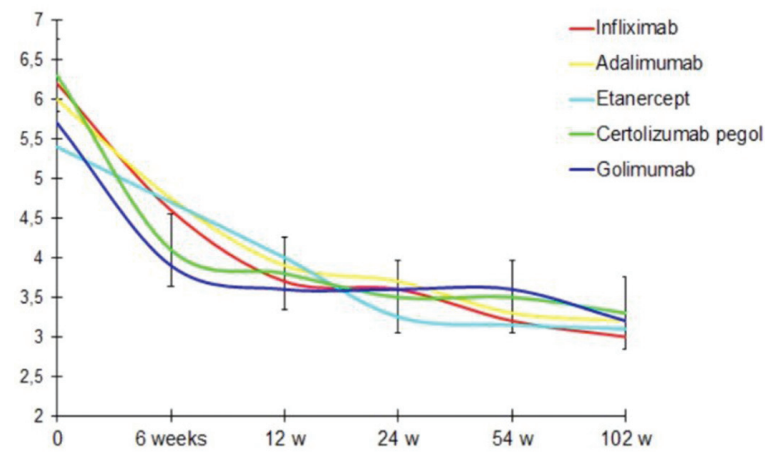

Abstract AB0433 - Figure 1. The dynamics of the disease activity index DAS28 in patients with RA receiving different TNF-a blockers

Conclusions: According to the RWD from the North-Western Biological Treatment Cohort, the efficacy of all the TNF $\alpha$-inhibitors and rituximab in RA treatment 